\title{
Parking Navigation and Payment System using IR Sensors and RFID Technology
}

\author{
Krishna Gopal Agrawal \\ Department of Information \\ Technology \\ Smt. Kashibai Navale College \\ of Engineering \\ Pune, India
}

\author{
Shubham Khandelwal \\ Department of Information Technology \\ Smt. Kashibai Navale College of Engineering \\ Pune, India
}

\author{
Shrey Sadhani \\ Department of Information \\ Technology \\ Smt. Kashibai Navale College \\ of Engineering \\ Pune, India
}

\author{
Roshi Ahuja \\ Department of Information \\ Technology \\ Smt. Kashibai Navale College \\ of Engineering \\ Pune, India
}

\author{
Sheetal Koul \\ Department of Information Technology \\ Smt. Kashibai Navale College of Engineering \\ Pune, India
}

\begin{abstract}
The main problem in today's crowded parking facility is congestion and finding a vacant parking space. In this paper, a navigation method is proposed that minimizes the parking time, based on collected real-time vacancy information of parking slots. In the proposed method, a central server in the parking facility collects the information (using IR sensors) and estimates the occupancy of each parking slots. Then, the server uses this information collected in real time to calculate the best suitable parking slot for the user upon request. This path is then sent to user's smart-phone as response by the server which will then be displayed on an android application. This leads to the introduction of an eco-friendly payment system (using RFID technology), wherein no use of paper takes place. Automatic deduction of parking charge is taken care of on the server side, from users via RFID account and notification via SMS or Email is generated.
\end{abstract}

\section{Keywords}

Parking navigation, RFID, Infrared sensors, Smart parking, Parking Application.

\section{INTRODUCTION}

Looking at the current scenario in parking system, it is observed that it is not efficient at all. The current parking areas have no management system i.e. people randomly park their vehicles in these large parking areas according to their convenience on either entry or exit. And also it is not easy for a car driver entering a large parking facility to know which parking zones are vacant. Moreover, once a car is stuck in a congested area, it even takes longer to get out of the area. This leads to greater time consumption and requires more manual labor. Also, this causes traffic jams and sometimes wastage of parking spots leading to lesser revenue generation. In this paper, an Android application will be developed that will enable a user to send information like his duration of stay for parking spot over the network without giving out personal information to the parking facility server. This will give the user a shortest path to the most convenient parking lot near $\mathrm{him} / \mathrm{her}$ avoiding congestion in the parking lot. The aim is to bring this dream into reality using the software development kit (SDK) that has been provided by Android, and building a server which will gather information of all the available parking slots using IR sensors. Also, this would lead to the development of eco-friendly system wherein all the money transactions are paperless using the RFID technology.

\section{EXISTING METHOD}

The existing method is random parking of vehicles according to driver's convenience. In this method a person needs to guide each and every vehicle to appropriate locations which are many times not followed or even miss-guided. In this method, location reporting has to be done manually by the parking facility employee to the car driver. Also the payment system is still manual making the process tedious and lengthy. Cars have to stay in queue for their turn and on hand transaction takes place which is slow.

\section{RELATED WORK}

Paper [1], proposes a navigation method that minimizes the parking time based on collected real time information of parking slots. It had used the various algorithm on server side to route the vehicles for vacant parking slots. It had conducted simulation based evaluation using realistic model from a real parking facility.

In paper [2], a method is proposed for solving a problem encountered in parking lot management systems via RFID technology. It handled the management, controlling and transaction reporting and operation tasks for parking lots on various parts of the city. Check-ins and check-outs of the parking lots will be under control with RFID reader. Personnel costs will be reduced considerably using this technology. Parking tickets will not be used during check-ins and check-outs. This will help to avoid ticket-jamming problems.

In paper [3], a vacant parking slot detection and tracking system is proposed that fuses the sensors of an Around View Monitor (AVM) system and an ultrasonic senor-based automatic parking system. This helped the drivers to select the parking slots and support the parking control system by continuously updating the designated target positions.

In paper [4], Real Time Monitoring System for Parking Space Management Services proposed a system that provides live information to users for vacant parking lot and provides information to operators to monitor status of the parking lots. It uses the principles of queue theory. This queue system model enables the predictions of arrival and service time in the system through analysis and calculations. 
In paper [5], Design and Implementation of Smart Parking Management System Based on RFID and Internet proposed a parking management system based on RFID and internet. The system solves the problem of lack of parking space available.

\section{PROPOSED METHOD}

\subsection{Assumption}

It is assumed that car drivers have smartphones with application preloaded and internet connection available. It is also assumed that car have inbuilt RFID tags.

\subsection{Overview}

As soon as a car enters the parking facility through an automatic toll gate, its unique identification number i.e. RFID tag is scanned via RFID reader. Next, the android application of the parking facility routes the car according to its duration of stay and the availability in the parking lot. A server system uses an algorithm to route all the cars requesting for parking slot. For this, the server needs to know the vacant spots available in the parking facility, and for this it uses the IR sensors installed all over the facility. At the end, during exit the cars RFID tag is read again and money is deducted accordingly from the user's account, thus making the system eco-friendly.

\subsection{Server Side}

The Server side is the most important part of the system. It handles the total load of the users (car drivers) requests and replies them with appropriate routes. When the user enters the parking facility, he opens his application and enters the 'duration to stay'. This field data is then sent to the server for the best parking slot allocation. The server on receiving the users request runs the data through an algorithm which is specially designed to avoid congestion in the parking facility. According to the duration to stay the parking slot is allocated, wherein the server allocates the user with maximum time the farthest slot and the user with minimal time the nearest slot to the exit to avoid traffic jams inside the parking space. The allocation of the parking slot and the route to it is then communicated by the server to the user via the application in response to the user's initial request. While allocating the parking slots the server need to know about each and every slots status of whether being full or empty continuously. For this information IR sensors are installed in each parking slot transmitting their readings to the server in real time. The server will maintain an array memory to store the vacancy related data as $1 / 0$ where 1 being full and 0 being empty. So the server uses this data from IR sensors relating to the vacancy of the parking slots in real time to communicate with the user and provide him the best vacant parking facility. The second task of the server is also to manage the RFID account of the user. On the entry and exit the respective time logs are made to the server by the RFID scanners placed at the toll gates. When the user exits the place and the exit time is registered in the server, the calculation of amount takes place. The amount is calculated on the basis of the time the vehicle spends inside the parking facility. The cost slabs are preentered in the server and accordingly the amount is deducted from the users RFID account maintained by the database.

\subsection{Client Application}

Client application consists of the application on the user side. This application has a login page and a page to register for new customers. The application communicates with the server using internet connection. The application acts as a guide for the user to direct him to his parking slot. After logging in the app the user need to enter a field 'duration to stay' which is then communicated to the server. In response the app receives data from server regarding the parking slot to be used. This data is shown to the user in a graphical manner which can be easily understandable and interpretable.

\subsection{IR sensors}

Infrared sensors or the IR sensors are low frequency light emitting diodes which are placed strategically in each parking slot all over the parking facility. Each IR used in the system is a passive IR sensor which must be continuously in working phase and send its data to the server in real time. The hardware interfaces the data from IR sensors to the server. While reading this data in a continuous feed the server has predefined threshold limits to check if a car is parked in the parking slot or is it vacant. The minimum and maxim threshold for the frequency readings are decided upon the average ground clearance of each vehicle, wherein a sports car might have a very low ground clearance and a sports utility vehicle may have a very high ground clearance.

\subsection{RFID Technology}

RFID is radio frequency identification. To register the incoming and outgoing timing of the vehicle in the server database, usage of passive RFID tags is made. RFID technology is used to create a green payment system wherein there in no use of paper currency or wastage of paper by issuing of payment slips. There are two parts to this technology, as in, the RFID tags and the RFID readers. The RFID readers are installed at the entry and exit toll gates. At these entry and exit points the RFID readers will read the RFID tags unique to each car. These data logs will be made into the server database. Also each user is having a RFID account was he has some balance money. Automatic deduction of the amount will take place from these accounts at the exit point and the user will be notified via the mobile application thus saving resources like paper and time. 


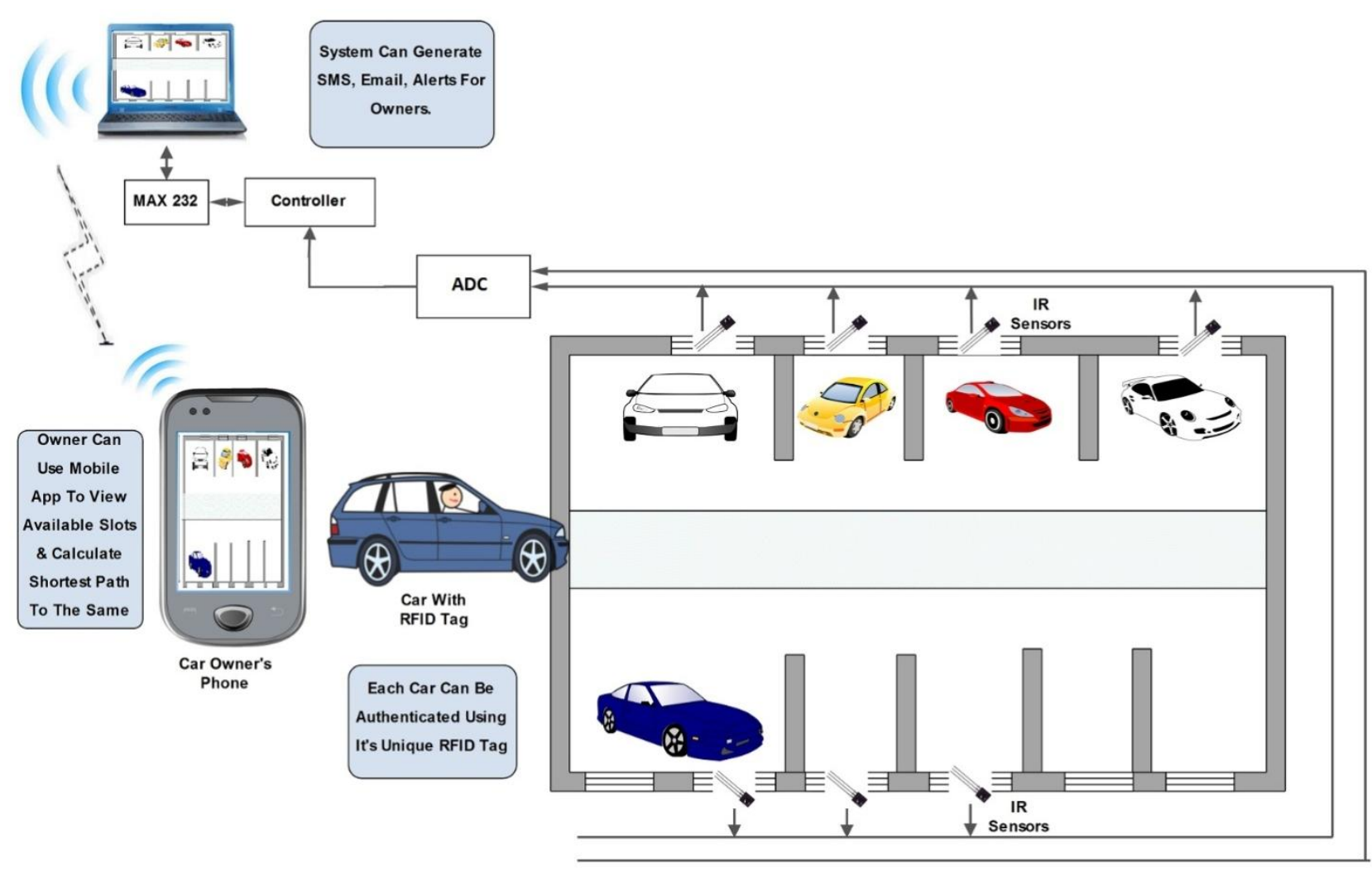

Fig 1: System Architecture

\section{CONCLUSION}

In this paper, a navigation method is proposed which minimizes the parking waiting time in a large-sized parking facility. It also helps in maximizing the revenue generation for the parking facility owners. It would also help reduce the need for man-power in the parking facility which would greatly reduce the cost and errors in the process. Also this method would minimize the usage of paper ensuring a green system.

This work can be further extended to booking of parking slots over a period of time from advance. The mobile application can be extended upon other operating systems such as iOS, Windows, etc. In the server, services can even be extended to the safety measures such as fire, theft, etc.

\section{REFERENCES}

[1] Masahiro Kenmotsu, Weihua Sun, Naoki Shibata, Keiichi Yasumoto and Mi-noru Ito, Parking Navigation for alleviating Congestion in Multilevel
Parking Facility, in Vehicular Technology Conference (VTC Fall), 2012 IEEE.

[2] Pala, Z. and Inanc, N., Smart Parking Applications Using RFID Technology, in RFID Eurasia $20071^{\text {st }}$ Annual, 2007 IEEE.

[3] Jae Kyu Suhr and Ho Gi Jung, Sensor Fusion- Based Vacant Parking Slot Detection and Tracking, in Intelligent Transportation Systems, 2014 IEEE.

[4] Thong Peng Hong, Che Soh, Jaafar and Ishak, Real Time Monitoring System for Parking Space Management Services, System, Process \& Control (ICSPC), 2013 IEEE Conference.

[5] Lanxin Wei, Qishenq Wu, Mei Yang, Wei Ding, Bo Li and Rong Gao, Design and Implementation of Smart Parking Management System Based on RFID and Internet, Control Engineering and communication Technology (ICCECT),2012 International Conference 